André Tosi Furtado; Luís Augusto Barbosa Cortez; Maria das Graças de Almeida Felipe; Raffaella Rossetto; Paulo Sérgio Graziano Magalhães; Manoel Regis Lima Verde Leal. "PUBLIC R\&D POLICIES FOR ETHANOL PRODUCTION IN BRAZIL", p.937-948. In Luis Augusto Barbosa Cortez (Coord.). Sugarcane bioethanol - R\&D for Productivity and Sustainability, São Paulo: Editora Edgard Blücher, 2014. http://dx.doi.org/10.5151/BlucherOA-Sugarcane-SUGARCANEBIOETHANOL_78

\title{
PUBLIC R\&D POLICIES FOR ETHANOL PRODUCTION IN BRAZIL
}

\author{
André Tosi Furtado, Luis Augusto Barbosa Cortez, \\ Maria das Graças de Almeida Felipe, Raffaella Rossetto, \\ Paulo Sérgio Graziano Magalhães and Manoel Regis Lima Verde Leal
}

\section{INTRODUCTION}

The Brazilian Ethanol Program began in 1975 and one of its main aims was to alleviate dependence on foreign oil importation. At the time Brazil was importing about $80 \%$ of its domestic needs causing a heavy burden on the economy.

The country focused on producing ethanol using sugarcane as feedstock and the Brazilian Government helped to finance new cane fields/ plantations and new distilleries. In less than ten years ethanol production jumped from 0.5 to about 10 billion liters/year. During the last 30 years the country has learned how to produce sugar and ethanol in a very cost-effective way and nowadays bioethanol is responsible for $60 \%$ of liquid fuels utilized in the Brazilian light vehicles fleet.

The amount of ethanol now produced in Brazil is significant in terms of the size of the domestic market (20 million vehicles) and it benefits the country in several other ways besides energy, such as:

- making Brazilian sugar more competitive;

- creating almost 1 million jobs;

- generating wealth in the rural sector;

- improving air quality in the large cities.

Nevertheless the Brazilian ethanol sector faces a new challenge in the form of the unprecedented opportunity represented by global warming resulting from GHG emissions.

Although Brazilian ethanol already presents excellent sustainability indicators, particularly regarding GHG mitigation, some aspects of its expansion have been the target of disproportional criticisms like:

- expansion of sugarcane would be somehow be related to deforestation in the Amazon;

- the production of biofuels, including Brazilian ethanol, would somehow constitute a threat to food production;

- the production of biofuels, including Brazilian ethanol, would generate a volume of emissions that would cancel its benefits.

Regarding the first point, deforestation in the Amazon has absolutely nothing to do with biofuel production in Brazil. The following arguments enable a better understanding of the issue:

- sugarcane is not produced in Northern Brazil.; the climate there is simply inadequate for sugarcane growing;

- sugarcane is a relatively small crop in Brazil (8 million hectares altogether, 4 for sugar and the other 4 for bioethanol production). The two most important national crops are soybean (22 Mha) and maize (12 Mha). The total area of Brazil is around 850 Mha hectares and the greater Amazon region accounts for nearly 450 Mha;

- creation of pasture land is probably the main factor driving the Amazon deforestation process (nearly $200 \mathrm{Mha}$ ).

The second factor has to do with competition with food crops. Production of food in Brazil has steadily increased over the last 30 years. Brazil is now the largest exporter of many commodities 
including: meat (beef, poultry and pork), sugar, coffee, soybean $\left(2^{\text {nd }}\right)$, and orange juice.

The third argument has to do with sustainability aspects such as water use, soil depletion and land use. Some of those aspects were simply not very important in Brazil in former times due to the small amount of ethanol produced and even today, as has been mentioned, it only occupies around 4 Mha, or $0.5 \%$ of Brazilian territory.

However, when the intention is to expand present ethanol production tenfold, (Cortez, 2002) then the land required for sugarcane production to meet such ethanol and sugar requirements may be as much as 35 Mha. The main conclusion of a study conducted by Leite (2005 and 2009) is that if ethanol production is to expand significantly in Brazil, then a great R\&D effort will be necessary to decrease the demands made on all the resources involved, such as land, water, fertilizers and others.

To that end, several research initiatives have recently begun the most important of which involve EMBRAPA (Agro-energy Center), Petrobras Biofuels Division, and the Bioethanol Research Center-CTBE created by the Brazilian Ministry of Science and Technology.

Furthermore, the São Paulo Research Foundation - FAPESP has supported a study to identify R\&D needs throughout the sugar-ethanol production chain. Since 2006, a series of 18 workshops has been conducted involving: Paulista Agribusiness Agency - APTA (including IAC), DEDINI, EMBRAPA Instrumentation, the Federal University of São Carlos, the Sugarcane Research Center-CTC, the University of São Paulo-USP, the Paulista State University-UNESP, and the State University of Campinas-UNICAMP.

\section{THE PROMISE OF BRAZILIAN BIOETHANOL}

Brazil is a developing country that has become a major producer and exporter of agricultural and agro-industrial products in recent decades and among those products is sugarcane ethanol. In the last ten years, Brazil has become the world's leading exporter of sugar, accounting for 30\% of world exports of the product. This has been achieved despite all the protectionist trade barriers that were raised against this agro-industrial product, and without any question it has led to the enhancement of Brazilian sugar's competitiveness in the international market. No other country has such low costs and flexible supplies as Brazil.

The same competitiveness is repeated in the case of bioethanol produced from sugarcane. No other country can presently offer such favorable conditions in terms of cost and supply expansion possibilities as Brazil. The loss of first place in the production of bioethanol to the United States in recent years can only be understood in the light of the high tariff barriers that the US government imposes to protect its domestic markets and the high subsidies that it grants to its own agricultural producers. Brazilian ethanol produced from sugarcane is both more economical and more efficient in terms of carbon dioxide balance (GHG emissions), than the American ethanol produced from maize. This aspect is reflected in the fact that Brazil is now responsible for half of world exports of the product.

The current international context is marked by serious concern with the two major challenges:

- global warming largely caused by burning fossil fuels;

- national policies capable of reducing energy dependence on fossil fuels.

Against this background Brazil stands out very favorably, offering the world an alternative source of energy, bio-ethanol, with its great capacity for mitigating $\mathrm{CO}_{2}$ emissions.

The production of ethanol is not the only opportunity for developing sugarcane cultivation. That crop can also help to address other important challenges such as generating electricity from a renewable source and producing chemicals from biological raw materials. Far from being endowed with antagonistic goals, those industries and their markets are actually complementary and can benefit one another.

The performance of Brazilian ethanol production is based on a technological system that initially had low production efficiency and high cost, but it was gradually improved due to a process of technological learning very much intensified by the pioneer Brazilian Ethanol Program known as the "Proalcool". The system was mainly developed in the State of São Paulo and is based on the si- 
multaneous production of sugar and alcohol, the so-called "Brazilian Model".

Technological advances have been obtained in both the agricultural and industrial phases. There is better utilization of waste from the production of sugarcane such as molasses, filter cake and vinasse. There has also been a considerable improvement in the productivity of the different varieties of cane obtained by means of traditional genetic selection techniques and improved methods of agricultural management. Although this system has achieved significant increases in productivity, it is now reaching its technological limits.

The current production capacity of Brazilian bioethanol is mainly based in the State of São Paulo, which accounts for approximately $60 \%$ of national production.

That leadership results from the following conditions:

- the best land and climate in the country for growing sugarcane;

- better transport infrastructure (roads);

- the best system of specialized research in sugarcane agriculture in the country;

- the presence of capital goods industries for the sugarcane agribusiness.

However, the expansion of sugarcane cultivation in São Paulo state will face serious territorial limitations if current optimistic projections are confirmed. The Canasat sugarcane information project (http:// www.dsr.inpe.br/mapdsr/eng/index.jsp) estimates that the 2008/2009 crop of sugarcane occupies an area of approximately 4.5 million hectares, exceeding by far any other crop in the state, although livestock farming occupies an area even larger (about 10 million ha). However, São Paulo state itself is only $3 \%$ of national territory. It is therefore expected that to maintain a suitable regional balance, much of the future expansion of the area planted with sugarcane will occur outside of São Paulo state.

Accordingly, the cultivation of sugarcane should mainly expand into the regions towards the Midwest and Northeast, where much of the recent expansion of the Brazilian agricultural frontier has been taking place. The expansion into the northern region ( $\mathrm{N}$ and $\mathrm{NE}$ ) would only be acceptable provided it occurred outside of the Amazon Forest.
Furthermore, the technological system on which the expansion of cane production has been based up until now is beginning to reveal important internal limitations. Major changes in the technological trajectory of the cultivation of sugarcane for ethanol production are needed if Brazil is to maintain its leadership in bioethanol production while maintaining its long-term social and environmental sustainability.

Such findings reaffirm the diagnosis that the State of São Paulo is destined to lead the development of the sugar agro-industry much more in the field of technology and logistics than in the aspect of production. That leadership will be in:

- the production of equipment and technologies;

- the transportation of bioethanol produced from the Central-West, to the Tietê-Paraná waterway by a pipeline system connecting it to the Paulinia Refinery, and the ports of São Sebastião (SP) and Angra dos Reis (RJ);

- the generation of new scientific knowledge through its universities and research centers;

- the qualification and training of human resources to enable them to meet the new challenges.

Beyond the trends revealed in current perspectives, the future of ethanol will depend on the evolution of technologies on both the supply and demand side.

On the demand side, bioethanol has the great advantage of requiring very few changes in current technological systems of individual road transport vehicles. When added to gasoline in concentrations of up to $10 \%$, practically no changes are needed in engines or fuel distribution systems. That fact, added to the innovation of the flex-fuel engines increasingly adopted in Brazil and the United States, that allow vehicles to use either ethanol, or gasoline or mixtures of the two, offers the consumer far greater freedom of choice.

However, we should not ignore the possibility that major technological breakthroughs may occur in the transport system leading to the widespread adoption of hybrid cars or electric cars. Even in that case, other opportunities will open up for sugarcane: as a renewable source of electricity, 
in the direct use of ethanol in hybrid engines; or possibly the use of ethanol as an energy source to produce hydrogen. In our view, rapid technological change in the pattern of demand in no way threatens the position of sugarcane as a primary source of cheap renewable energy and ethanol as a clean combustion fuel.

On the supply side, there are technological challenges. As a result of heavy investments being made by countries in advanced conversion technologies (second and third generation technology), a new horizon of possibilities has appeared. Those technologies can broaden the spectrum of biological materials that can be used in the production of ethanol to include cellulose and hemicelluloses, which are far more abundant and have lower production costs than starches and sugars.

\section{THE GUIDING PRINCIPLES OF SUSTAINABILITY AND THE EXPANSION OF SUGARCANE AND ETHANOL PRODUCTION}

Seizing the opportunity of producing ethanol to supply both internal and external markets requires a new level of technology that takes into consideration social, economic and environmental indicators. The new level of production must fit in with the basic principles of sustainability.

\subsection{Basic conditions of sustainability}

The concept of sustainability applied to a product and/or a production process implies an understanding that the production must be: economically viable (i.e., competitive with respect to other similar products without any need for subsidies); socially fair (i.e., the economic feasibility of production may not be based on the exploitation of workers, the existence of inadequate working conditions, should not induce concentration of income etc.); and environmentally adequate. The environmental dimension is the largest, because it involves various aspects related to impacts (on air, water, soil, and biodiversity) in different horizons of time (short-term impacts and long-term cumulative effects) and with different geographical coverage (local, regional or even global impacts).
In regard to the production of ethanol from sugarcane in production conditions typically found in Brazil, the economic dimensions of sustainability has not been object of discussion so far since Brazilian ethanol is the only biofuel that is economically viable without subsidies as compared to gasoline, even at current levels of oil prices (45-50 US $\$ /$ barrel). Moreover, when that analysis is done for a horizon of 20-30 years and takes into account a significant expansion of production, then the economic dimension needs to be further prioritized. Thus, the medium to long-term goal will be to keep the production costs of ethanol as low as they are now even for levels of production from 4 to 5 times higher and even with the use of so-called second generation technology.

As regards the social dimension, the principles of sustainability discussed internationally delineate the conditions that are considered to be minimally adequate with respect to the principles of the International Labor Organization namely: respect for human rights, and the improvement of the living conditions of the social groups directly involved. What draw negative attention from the international community to the production of ethanol in Brazil is the harsh working conditions imposed on cane field workers. Often the disclosed irregularities are associated to slave labor and inhumane working conditions. Also in the socialeconomic field there is the common criticism that the ethanol production induces the concentration of income and of land tenure. The environmental dimension, as mentioned above, is now even broader. Based on the principles of sustainability intensely debated in Europe, the priority goal is to reduce net emissions of greenhouse gases (GHG) in comparison with those of the life cycle of the substituted fuel - gasoline, in the case of its substitution by ethanol. In addition to the issue of the net balance of GHG emissions, there is particular concern about the direct and indirect impacts of the changes in land use because of the associated impacts on biodiversity and the provision of food.

Ethanol production in Brazil is also criticized for the fact that the areas of sugarcane cultivation are extensive monocultures or "plantations" and therefore constitute a potential negative impact on biodiversity. The possible impacts on the quality 
and availability of water, fear of contamination of groundwater associated to the disposal of vinasse, and excessive use of chemicals, including some banned in developed countries are also frequently mentioned concerns. Evidence of unsustainable social and environmental productive relations associated to growing sugarcane, should be located, however, within the context of socio-productive practices that have prevailed in Brazilian agriculture since its emergence in the colonial era and are with us up until the present day, even in the more advanced segments of agribusiness. It would not be very costly, however, and would not in any way jeopardize the economic viability of producing ethanol if socially and environmentally sustainable productive practices were adopted. Such new practices will have important consequences for the future R\&D agendas of the public and private sectors in Brazil, and, consequently, for the R\&D agenda of the State of São Paulo.

\subsection{Recommendations for public policies}

All actions related to the expansion of ethanol production and the development of new technologies must be guided by the central objective that future production must be sustainable in the broadest sense.

On the economic side, there is a need to reduce transport costs. If energy and cost-efficient modes of transport were used then GHG emissions and overall costs would be lower. Assessments have shown that in a country of continental dimensions like Brazil, the present form of transporting ethanol by truck to the major domestic consumer centers and to the ports for exports represents a very costly overhead.

Better use of sugarcane products and byproducts is essential to reduce production costs and in some cases, to obtain better results in avoiding GHG emissions. In the short and medium-term, the generation of a bioelectricity surplus using by-products and marketing it in the power grid is the best opportunity. Therefore, we recommend the large-scale generation of bioelectricity to better exploit the existing potential.

The so-called second-generation technologies need to be developed to enable the production of biofuels from cellulosic biomass, and the country needs to master the production processes involved. In the case of sugarcane, it would be possible to use residual biomass (bagasse and cane straw, called "trash"), and increase productivity (per tonne of cane per hectare), with the added advantage that such products are available at the factory gate.

In regard to social aspects, a central concern in view of the socio-demographic structure of rural areas is the generation of both skilled and unskilled jobs. There must be progressive qualification of persons to perform new functions that will arise directly from the mechanization of harvesting and tillage. However, it is essential that the process should occur in a balanced manner compensating the jobs destroyed by mechanization with the offer of new, more qualified and better-paid jobs.

If the production of cane sugar were to be done mainly in small and medium-sized rural properties by independent suppliers, there would be potentially less social tension and better distribution of income, since small farms preserve more manual work. Key issues are: how to avoid excessive verticalisation in the production of ethanol; and how to provide conditions for small and medium farmers to be competitive (e.g., having access to technology, gaining access to machines and implements).

Therefore, it is essential that there be a technological breakthrough that would enable the adoption of less capital-intensive harvesting technologies thereby preserving employment while at the same time being less aggressive to the environment.

Looking at the environmental aspects, it is possible to reduce the impact at this level through an agro-ecological land-use plan. That will minimize the problems associated to the misuse of land, although it is would be of an indicative nature rather than regulatory. Accordingly, it is essential to monitor the results and find ways to improve them. More specifically, such zoning would help to avoid the excessive concentration of sugar as a single activity in a given region as is already the case in certain regions of the state. Much can be done to induce the diversification of crops, providing greater diversity to the agricultural regions, without hurting the principle of economic profitability.

The "Agro-ecological Land Use Plan" should seek to minimize the direct impact of the change of land use, targeting the expansion of cultivated 
areas into degraded lands, occupied by extensive grazing and livestock. In that way, the expansion of ethanol production could take place without any need for deforestation.

The negative environmental impacts of the cultivation of sugarcane are not restricted to deforestation. The burning of sugarcane before harvesting involves significant emissions of pollutants into the atmosphere and the waste of an important energy resource. Policies to encourage harvesting without burning, and making use of cane straw in all Brazilian states, are essential prerequisites of the new trajectory of sustainable ethanol in Brazil. Similarly, the development of alternative tilling methods for cane needs to be encouraged, first in terms of research and development, and then to define the best techniques to be actually used.

Legal Reserves (RL) and Permanent Protection Areas (APP) are defined by Brazilian legislation. However, even in the state of São Paulo those laws are not fully complied with. What can be done for the effective enforcement of legislation, and in the shortest time possible? New economic instruments are needed here.

Little is known about the effects of the use of fertirrigation in terms of GHG emissions. More specifically, little is known about methane and nitrous oxide emissions associated to the application of fertilizer industry products as a whole. This is a topic that requires further research. Still on the subject of fertirrigation, its long-term effects and the possible contamination of groundwater are also unknown aspects. There is law in São Paulo on the disposal of vinasse, but not in the rest of Brazil. Even in São Paulo, that law is based on limited current knowledge.

The use of chemicals banned in other countries, and in some cases also banned in Brazil must be effectively curbed and the use of fertilizers and agricultural chemicals must be effectively minimized.

In short, there must be a national agenda to lead the sustainable production of ethanol. That agenda should be proactive, defining actions to anticipate the criticism and questioning stemming from all segments of both Brazilian and international society. Furthermore knowledge needs to be produced regarding all the important pending issues and not only in regard to the mitigation of the impacts so often referred-to.

\section{A NEW AGRICULTURAL MODEL FOR SUGARCANE PRODUCTION}

Agriculture is the key to the success of Brazilian ethanol. An important part of the productivity gains of ethanol were achieved in agriculture. The role of research, particularly in São Paulo, has been the key to that success. The advances obtained resulted in a trajectory based on traditional techniques of plant breeding and the use of state of the art management techniques in agriculture. To avoid that trajectory's becoming exhausted by diminishing returns there must be changes in the degree of agricultural innovation. Advances in the agricultural phase of production are essential to maintain the competitiveness of Brazilian ethanol since sugarcane itself accounts for $70 \%$ of the overall costs of any ethanol plant.

Listed below are some guidelines for an R\&D policy designed to construct a new development model for the cultivation of sugarcane:

\section{1) Productivity of sugarcane}

1.a) Promote basic research on photosynthesis in order to understand the main mechanisms involved in the conversion of light into biomass. The photosynthesis reaction is the most important one in the process of biofuel production and is still very little studied in Brazil.

1.b) Encourage research in biotechnology to serve as a basis for increasing productivity by conventional breeding or transgenics. Obtaining transgenic plants is a necessary step. More studies should be developed to regulate transgenic plants in a manner consistent with our reality, and issues related to intellectual property rights should also be considered.

1.c) Continue research development for sequencing the sugarcane genome.

1.d) Promote the development of varieties of sugarcane with high biomass production with a focus on energy use as a primary function for the optimization and selection of clones and/or varieties. In that context, the clones may be selected in terms of primary energy, i.e. Mega-Joules per ton of sugarcane (MJ/tc). This concept considers the total energy of sugarcane, including fiber, sucrose and reducing sugars, i.e. the selection of so-called "energy cane". 
1.e) Brazil must make strenuous efforts to establish a collection of sugarcane germoplasm for public use, representative of genetic diversity in the Saccharum complex. The largest collection of germoplasm includes many representatives of the Saccharum complex and is now under the management of the Sugarcane Technology Center (CTC) and is restricted to this institution. There are three other collections belonging to existing sugarcane improvement programs: the Inter-University Sugarcane Development Network (Ridesa), the Agronomic Institute of Campinas-IAC (represented mainly by parents for crossing purposes, with few representatives of the Saccharum complex); and the collection of CanaVialis (Monsanto). Any process attempting to replicate the USDA and/or the CTC collection will necessarily be subject to limitations. It is therefore necessary to establish policies for the use and introduction of access to the "Saccharum Complex". Priorities should be given to species with greater potential for use in breeding, and to $S$. officinarum and S. spontaneum. However, the Erianthus and Miscanthus genera are both adapted to unfavorable environmental conditions like cold and drought, have high biomass-producing capacity, and are therefore very interesting for bioenergy purposes.

\section{2) Interaction of sugarcane and the environment}

2.a) Investigate molecular mechanisms and their physiological responses and undertake the biochemical characterization of the various cultivars.

2.b) Study the impacts of climate change on the cultivation of sugarcane.

\section{3) Nutrition of sugarcane and fertilizers}

3.a) Encourage studies on new sources of fertilizer, with higher efficiency and less impact on the environment; develop microbial systems aimed at greater efficiency in the use of nutrients; and conduct genetic improvement for higher yields in marginal soils with decreased need for fertilizers.

3.b) New studies in fertilizer use for sugarcane should investigate: the question of fertilizing the subsoil by means of long-term studies experimenting with doses higher than those currently employed for the purpose of improving the chemical environment for root growth in the subsurface which can be especially interesting in regard to those regions with poor soils and very dry winters into which the cultivation of sugarcane tends to expand; the management of long-term fertilization with $\mathrm{N}$ in sugarcane raw; the contribution of biological $\mathrm{N}$ fixation (BNF), one of the possible reasons for the use of smaller quantities of nitrogen in sugarcane in Brazil, has an important role in nitrogen nutrition and should be further investigated, because there is still controversy about the magnitude of their contribution agronomic; assessment of environmental fertilization of sugarcane in an energy-balance perspective, especially in regard to the production of greenhouse gases.

3.c) The use of irrigation in agricultural production, mostly needed in the states of the CentralWestern and North-eastern regions of Brazil but it also increases productivity in areas such as the west of São Paulo State. Studies are needed to minimize water use and costs in general, but also new equipment and technologies, need to be evaluated.

\section{4) Control of pests and use of pesticides and fungicides (agrochemicals)}

4.a) Bioecological studies involving the biological control of pests are technologies that aim at sustainability and should be encouraged. In particular, alternative intensive monitoring and control methods for the control of the giant cane-borer, $\mathrm{T}$. licus, should be sought for immediately as the current control methods are empirical and inefficient.

4.b) Studies must be conducted identifying the effects of trash and the new agro-ecosystem formed by the harvesting of unburned cane. New soil pests, natural enemies and entomo-pathogens may be present.

4c) Evaluation of the efficiency of the biological pest control (biological and microbial control should be favored by mechanical harvesting).

4.d) Studies for monitoring pests (including GIS) and for adequately sampling and rationally controlling them, either through biological or chemical means.

4.e) Studies on the environmental impacts of chemicals and alternative controls on the agro- 
ecosystem (selectivity, occupation of niches, biological imbalances, resurgence of pests, resistance management).

4.f) Search for and identification of new agents for biological control, involving epizootiological studies of diseases, pest population dynamics, selection of strains and biological control agents.

4.g) Feasibility studies on farmer use of already synthesized pheromones for pest monitoring and control, and conducting research aimed at developing and synthesizing other pheromones in the short, medium and long terms.

\section{5) Use of waste by-products in ethanol production from sugarcane}

5.a) There is a lack of basic research and studies of a technical-economic-social-environmental nature to characterize the impacts and/or determine other forms of direct use of the stillage and by-products, such as concentrating vinasse, biodigestion, incineration etc. The recycling of nutrients is already common in sugarcane agribusiness in the form of returning solid and liquid wastes such as filter cake, ash, and especially vinasse to the fields.

5.b) The development of technology for the production of ethanol from cellulosic materials, mulch or trash left over in the process of harvesting unburned cane (stalks and leaves), which may produce vinasse with different physical-chemical properties than the present-day vinasse. That requires the performance of studies aimed at understanding the possible impacts caused on the land and environment.

\section{6) Direct planting of sugarcane}

6a) There is a need for research and development of planting machinery with a planting capacity of the same quality as manual planting.

6.b) Research and development of procedures aimed at reducing the movement of soils and soil compaction are needed, allowing for minimum tillage techniques to be applied without loss of productivity.

6.c) New technologies should address issues relating to planting machinery adapted to minimum tillage conditions and the presence of trash and with a planting quality superior to that obtained in traditional planting conditions.

\section{7) Consolidation of green cane harvesting (without burning), recovery of trash}

7.a) Analyzing the group of existing technologies, we can conclude that they do not satisfactorily meet requirements in terms of current environmental legislation, efficient recovery of biomass, sustainable use of soil and the ability to operate in areas with the greatest topographic limitations. We must invest in the development of harvesting technology to circumvent those problems and allow for the full exploitation of sugarcane. A major challenge is the development of a system of mechanized harvesting covering the recovery of trash, at least partially, with cost and quality that allow its energy potential to be exploited. It is necessary to encourage the development of specific solutions for the mechanization of sugarcane growing focused on reducing the traffic involved in the tilling process and fostering precision agriculture.

7.b) Development of sampling systems capable of operating on slopes of over $12 \%$, associated to a machinery that can operate with two lines requiring, in principle, increased gauge and improved stability.

7.c) Semi-mechanized harvesting aids. The development of systems to facilitate the manual labor may be a trend in areas where mechanical harvesting is not the appropriate solution. That will help minimize the social problem created by totally mechanized rapid harvesting of raw cane.

7.d) Trash is one of the options for increasing the availability of biomass for co-generation plants in the factories and is also needed in the field to protect soil and improve tillage. Further studies should be conducted to determine what the minimum quantity of plant residue is that should remain in the soil to get the maximum benefit from that coverage, and how much can be released for co-generating purposes.

\section{8) Management and monitoring of sugarcane cultivation}

8.a) The development of real time (in loco) sensors for the inspection or monitoring of the 
culture to avoid additional operating costs is a major target of industry and research.

8.b) Investments must be made to enable the standardization of the on-board electronics of agricultural machinery and communication between equipment of different manufacturers using open protocols.

8.c) Encourage research in robotics technology in the search for greater precision in operations, safety of operators and the highest quality of field operations and equipment delivered to the mill.

8.d) Development of equipment to improve the monitoring of sugarcane throughout the cycle from planting to harvest, including the improvement of productivity of the monitoring devices by incorporating information on the quality of the cane.

\section{NEW MODEL AND INDUSTRIAL END USES OF ETHANOL}

The current production system based on the simultaneous production of sugar and ethanol, located near the consumer market, and supported by the road transport system must be revised in order to become sustainable. The new production system will be located in the hinterland far from the markets and specialize in the production of ethanol alone. The conditions to ensure profitability of this new support system will be a much more efficient use of by-products of sugarcane capable of producing energy and a far more economical transport system.

The following is a list the main policy guidelines for the establishment of a new design:

\section{1) Logistics and transport of cane ethanol}

1.a) Establish an integrated sugarcane agribusiness logistics system addressing the transport of sugarcane, bagasse (transporting surpluses to a central processing unit if necessary), trash, ethanol, sugar and the vinasse used in fertirrigation.

1.b) Develop studies to optimize the transport of ethanol and reduce its costs. The new type of transport could be done through the grouping of units (clusters), and implementation of intermodal transport (river, ethanol pipelines etc.).

\section{2) Reducing the use of water and energy in the industrial process}

2.a) Promote the implementation of projects that reduce the uptake of water per ton of cane processed. Establish a State Plan for release during the first phase of the paradigm "Zero Water" in the production of ethanol.

2.b) Encourage the implementation of projects that optimize the use of cane bagasse and cane trash to produce energy, ethanol and sugar, and the use of other products resulting from the processing of biomass.

2.c) Encourage the production and marketing of electricity surplus, through the promotion of specific auctions (according to the Aneel regulatory agency rules) and the design and construction of core collectors of electricity to reduce investment in the grid network in more remote areas of the state, creating rules that establish who should bear the costs of interconnection.

2.d) Promote the generation of power from the stillage, through its biodigestion, and employing the biodigested stillage residues in fertirrigation in the cultivation of sugarcane. Provide incentives to other forms of stillage exploitation. There is a lack of basic research and studies to characterize the technical, economic, social and environmental impacts stemming from the direct use of the stillage, such as applications of concentrated vinasse, biodigestion, incineration etc.

\section{3) Use of by-products}

3.a) Introduce the concept of utilization and valorization of by-products like yeast, higher alcohols, and others in Brazilian industrial policy.

3.b) Establish an integrated state plan to facilitate the collection of agricultural waste (trash), to be transformed into ethanol or electricity.

\section{4) Environmental control of the application of wastewater}

4.a) Establish a plan for environmental control and monitoring of the use of antibiotics in producing ethanol and in stillage applied to soil. 


\section{5) Second generation technology}

5.a) Develop and deploy second generation ethanol production technology based on hydrolysis induced by chemical means (acid hydrolysis) or biological means (enzymatic hydrolysis) for the recovery of ethanol from ligneous-cellulosic cane waste. That would increase the production of ethanol and/or biofuels and other products in the state, without increasing the area of sugarcane planted.

5.b) Develop and deploy second generation thermal conversion technology known as gasification and pyrolysis in the production of chemicals, biofuels and electricity, using ligneous-cellulosic sugarcane waste. Gasification for the production of electricity creates the possibility of sugarcane increasing its participation in the generation of electricity in the country thereby reducing the environmental impacts stemming from the implantation of large hydroelectric projects Gasification for producing synthetic biofuels (Fischer-Tropsch) will open a new route, possibly the most economical being hydrolysis, to obtain biofuels from ligneous-cellulosic waste, or even from whole cane. Together with pyrolysis it offers a promising new possibility of obtaining bio-products that could replace those derived from petroleum.

\section{6) Development of ethanol and sugar chemistry}

6.a) A whole range of bio-products can be developed by using sugarcane derived biomass, sugar and/or ethanol and transforming them into other products with added value.

\section{7) Industrial process control and monitoring}

7.a) Deploy faster and more accurate methods of measurement on line to reduce losses and enhance control throughout all stages of sugarcane processing.

7.b) Create and maintain updated (through lines of credit and encouragement and special training programs) reference laboratories for the monitoring and supervision of the quality of ethanol fuel sold in the state.

7.c) Create a state "quality seal" (or actively participate in a national seal being developed by the Inmetro) for the sugar-alcohol sector, resulting in the adoption of quality standards for products and in implementing a traceability system to control all links of the production chain and marketing.

\section{8) Synergy in the production of ethanol and biodiesel}

8.a) Facilitate integrated production of ethanol and biodiesel in the state, encouraging the use of ethanol in the biodiesel production chain and the substitution of diesel fuel used to harvest and transport cane, using instead the biodiesel produced in the plants themselves.

8.b) Develop technology enabling the substitution of diesel oil by ethanol or biodiesel fuel in cane harvesting and transport.

\section{TOWARDS A NEW MODEL FOR POLICY INNOVATION}

Considerable investments in R\&D in the areas of agricultural production and industrial processing are necessary in order to achieve the desirable scenario of a new model for sustainable agricultural and industrial production of ethanol. That model will not arise from a simple progressive and automatic adjustment of the current production system to market stimuli and incentives alone. It presumes there will be more effective leveraging of a far greater volume of resources and the coordination of initiatives to introduce considerable changes in the current path of production in the sugarcane agro-industry.

Besides the technological goals listed above, it is up to public policies in combination with the relevant stakeholders in the sector to improve the scientific density of the technological innovation system in Brazil. To that end, two other points deserve attention: the need for constant training of human resources at high level and the need to undertake basic research.

If Brazil wants to continue heading the bioethanol field, it will have to convert its current advantage in production into effective scientific and technological leadership. That could be achieved through the publication of researcher's work in important journals, and through its companies' leading the industry in terms of registering new patents 
making it clear to the international community how well the country manages staff qualification and technological developments in the sector.

To achieve such a quantum leap instead of the essentially incremental progress that has been the tradition up until now, the institutions and agencies involved in fostering such activities at state and national level must mobilize resources for innovation and to provide good training for staff in both the agricultural and industrial stages of production. The quantum leap will only occur if there is an articulated and coordinated policy on innovation.

Accordingly, it is very important to invigorate the public sphere of science and technology associated to ethanol by:

1. Revitalizing Research Centers of the APTA (IAC. IB, IZ, ITAL, IEA and others).

2. Promoting mechanisms of cooperation with other public and private centers (IPT, CTBE, CTC and the universities themselves) as for example in the case of Fapesp's Bioen Program in which an expressive volume of resources is directed to applied technology issues in association with the private sector (Oxiteno, Dedini and Braskem).

A policy with national dimensions is essential and must contemplate the following actions:

1. To support graduate and post-graduate programs which operate in subjects and themes related to biofuels, both in the agricultural phase and in the consumption phase. To reinforce programs such as Fapesp's Bioen, which encourage basic research related to sugarcane and bioethanol, and which promote cooperative research between University-Corporation.

2. Providing mechanisms for coordination and joint actions of state agencies (Fapesp, Department of Development, APTA, IPT and other research institutions, state) and federal government agencies (Embrapa, Inmetro, ABNT, ABDI, Finep, CNPq, BNDES) for the creation and implementation of technology programs for Ethanol (Second Generation Technologies, Flex Hybrid Cars, Power Pole etc.).

3. Creating mechanisms for the integrated use of Sector Funds, Resources and the Participation of Aneel's special ANP, and Fapesp in promoting coordinated action between the Federal
Government and State; consolidating programs such as the Fapesp Bioen Program to encourage basic research related to sugarcane and bioethanol; and promoting cooperative research activities between the Universities and Private Enterprise.

4. Supporting the FAPs in structuring an agenda for research conducted in other states with the greatest potential for the expansion of sugarcane (MS, MT, GO, TO, BA, MG, PI, MA).

5. Promoting technology-based companies, suppliers of goods and services to the sugaralcohol sector, and the creation of technology parks in bioenergy (as for example, Vale in São Jose dos Campos, and the Energy City of San Carlos) through Sebrae, BNDES, the Bank of Brazil, Finep and the Development Department of the São Paulo State Government.

6. Developing an agenda for international cooperation in research in the area of bioenergy with strategic countries endowed with the capacity for innovation or of geopolitical importance, articulated by Fapesp, CNPq, Finep and Embrapa.

7. Translating efforts to implant the certification of ethanol (Inmetro and Europe) into items on the research agendas together with technological innovation to overcome the associated technical difficulties.

8. Integrating ethanol-promoting policies into the national energy policy and putting them on the national climate change agenda making use of the CDM to accelerate technological innovation and foster demonstration projects (e.g., recovery of straw and trash and their use in CHP) in the sugar-alcohol sector.

9. Developing a policy to encourage Patent and Intellectual Property registrations in the sugaralcohol sector in collaboration with the Inpi.

10. Consolidating a promotional and regulatory system at both state and federal levels that fosters the adoption of new technologies consistent with the new model of ethanol production.

11. Making efforts to create and establish Legal and Regulatory Frameworks for the development of the sugar-alcohol sector that reflect all internal and external requirements (e.g. 
certification) in order to construct a better scenario over the coming years or decades. An example of a successful regulatory framework led by the SMA/SP was the State Law that was implemented to put an end to burning and had important impacts on the process of mechanization, reduced low grade employment (casual day-workers), and induced positive effects on other Brazilian regions, as well as improving the image of Brazilian ethanol.

12. Creating lines of low-interest credit (BNDES, Banco do Brasil) and tax abatement mechanisms for federal taxes (IPI) and state taxes (ICMS) destined to stimulate financing and acquisition of more energy-efficient and socially and environmentally sustainable equipment (high-pressure boilers, co-generation equipment, harvesters with low levels of soil compaction, biodigestors for vinasse etc.).

\section{FINAL CONSIDERATIONS}

In the short term, Brazil needs to implement a series of public policies to promote the long-term competitiveness of its bioethanol.

If the country wants to respond to criticism, particularly foreign criticism, as to how large quantities will be produced, it has to focus not only on cost reduction but also sustainability aspects such as soil use, fertilizers, water use, and others.

To a large extent the answer to those questions lies in the development of technologies that

\section{REFERENCES}

FAPESP. Public Policies for Ethanol Project. Available at: $<$ www.apta.sp.gov.br/cana $>$.

CANASAT. Available at: <http://www.dsr.inpe.br/mapdsr/ eng/index.jsp $>$.

CORTEZ, L. A. B.; GRIFFIN, M.; SCANDIFFIO, M. G.; SCARAMUCCI, J. A. "Worldwide Use of Ethanol: a Contribution for Economic and Environmental Sustainability" Sustainable Development of Energy, Water and Environment Systems, Dubrovnik, Croacia, 2-7 June 2002.

FAPESP. Bioen Program. Available at: <http://www.fapesp. br/materia/3254/pesquisa-para-inovacao/programafapesp-de-pesquisa-em-bioenergia-bioen-.htm>. will help to decrease negative impacts by requiring less land and at the same time guaranteeing longterm sustainability.

Those technologies are not available yet. They need to be developed, mainly in Brazil, because the country hosts nearly $30 \%$ of all cultivated sugarcane areas in the world.

Nevertheless in Brazil it is a relatively small crop area when compared to the areas under maize, wheat, rice and soybean.

The implementation of more R\&D efforts will be a big challenge for Brazil to face because the necessary improvements require well-established research infrastructure and human capacity. Furthermore, the gains obtained in the last 30 years after the demise of the Proalcool, were obtained in the face of only moderate difficulties as compared with the difficulties involved in the development of second generation technologies.

Brazil is reasonably well prepared for the challenge however as the country already produces more than 10,000 PhDs a year and has an important research financing organizations with agencies such as Fapesp, CNPq and Finep endowed with respectable funds.

The challenge is how to put together public and private research funds and pursue goals that can doubtless be achieved, but that must, at the same time give satisfactory answers to foreign consumers and publics, and help to satisfy domestic needs such as the one represented by the electricity demand looming in the near future.

LEITE, R. C. C. Study of large scale production of ethanol, its possibilities and impacts, aiming the partial substitution of world gasoline (Estudo sobre as possibilidades e impactos da produção de grandes quantidades de etanol visando à substituição parcial de gasolina no mundo), 2005 [in Portuguese]. See also: <http://www.cgee.org. br/prospeccao/doc_arq/prod/registro/pdf/regdoc2162. dpf $>$.

LEITE, R.C.C.; LEAL, M. R. L. V.; CORTEZ, L. A. B.; GRIFFIN, W. M.; SCANDIFFIO, M. I. G. "Can Brazil Replace 5\% of the 2025 Gasoline World Demand with Ethanol?"Energy vol 34/5 (655-661) 2009, 7p. 